DOI: 10.12957/demetra.2018.31340

\title{
Dialogando sobre as possibilidades e desafios das merendeiras nas ações de Educação Alimentar e Nutricional
}

\section{Discussing the possibilities and challenges of school's cooks in the actions of Food and Nutrition Education}

Kelly dos Santos Gomes

Alexandre Brasil Carvalho da Fonseca ${ }^{2}$

1 Universidade do Estado do Rio de Janeiro, Instituto de Nutrição, Departamento de Nutrição Aplicada. Rio de Janeiro, RJ, Brasil.

${ }^{2}$ Universidade Federal do Rio de Janeiro, Núcleo de Tecnologia Educacional para a Saúde. Rio de Janeiro, RJ, Brasil.

Correspondência / Correspondence

Kelly dos Santos Gomes

E-mail: kelde@hotmail.com

\section{Resumo}

Objetivo: Discutir o papel da merendeira no Programa Nacional de Alimentação Escolar, assim como suas possibilidades e desafios nas ações de Educação Alimentar e Nutricional. Metodologia: Pesquisa qualitativa, utilizando a técnica de Grupo de Diálogos. O grupo estudado foi composto por 23 merendeiras de uma cidade da Baixada Fluminense, Estado do Rio de Janeiro. Resultados e Discussão: O potencial educativo das merendeiras está apoiado nas relações de afeto que desenvolvem com os educandos e nas qualificações que realizam para desenvolver novas habilidades. Entretanto, a falta de tempo e de integração com a equipe escolar se apresentam como desafios para a realização da função educativa dessas profissionais. Conclusão: A função educativa da merendeira está permeada de possibilidades e desafios, sendo interessante valorizar seus aspectos potenciais para a Educação Alimentar e Nutricional e contribuir para a superação de seus desafios. Assim, será possível usufruir ainda mais do potencial educativo desse programa.

Palavras-Chave: Alimentação Escolar. Pesquisa Qualitativa. Educação Alimentar e Nutricional.

\section{Abstract}

Objective: To discuss the role of school's cooks within the Brazilian National School Feeding Program, as well as its possibilities and challenges in the actions of Food and Nutrition Education. Methods: Qualitative research, using the techniques 
of participant observation and Choice Work Dialogue. The studied group consisted of 23 school's cooks from a city in the metropolitan region of Rio de Janeiro state. Results and Discussion: The educational potential of school's cooks is based on the relationships of affection they develop with students and on the qualifications they perform in order to develop new skills. However, the lack of time and of integration with the school staff are challenges for the fulfillment of the educational function of these professionals. Conclusion: The educational function of school's cooks is permeated by possibilities and challenges; hence, it is interesting to value its potential aspects for Food and Nutrition Education and to contribute to overcome its challenges. Thus, it will be possible to enjoy even more the educational potential of this program.

Keywords: Scholl feeding. Qualitative Research. Food and Nutrition Education.

\section{Introdução}

O Programa Nacional de Alimentação Escolar (PNAE) é a política pública de nutrição mais antiga em vigor no Brasil. Sua implantação ocorreu em 1955, sendo na época chamado de Campanha Nacional de Merenda Escolar, visando garantir a alimentação escolar a todos os alunos da educação básica de escolas públicas ou filantrópicas.

Atualmente, alunos de todo o país, da creche ao ensino médio, passando pela educação de jovens e adultos, são beneficiados pelo programa. No ano de 2014, o PNAE beneficiou em todo o Brasil mais de 42 milhões de alunos, totalizando um investimento de 3,6 bilhões de reais. ${ }^{1}$

Santos ${ }^{2}$ destaca que diferentes estudos têm apontado o histórico vínculo da educação alimentar e nutricional com as políticas de alimentação e nutrição. Com o PNAE não é diferente, e dentre os objetivos deste programa consta a contribuição para a formação de práticas alimentares saudáveis dos alunos, por meio de ações de educação alimentar e nutricional. ${ }^{3}$ Desta forma, o programa configura uma excelente atmosfera para a prática de educação alimentar e nutricional (EAN), onde a escola ganha papel de destaque como espaço preferencial para práticas de alimentação saudável e aprendizado sobre os múltiplos significados da alimentação.

A escola também é reconhecida como um local privilegiado para a promoção de práticas alimentares saudáveis pelo Ministério da Saúde. Em 2006, em parceria com o Ministério da Educação, foram instituídas diretrizes para a Promoção da Alimentação Saudável nas escolas 
públicas e privadas em âmbito nacional, favorecendo o desenvolvimento de ações que promovam e garantam a adoção de práticas alimentares mais saudáveis no ambiente escolar. ${ }^{4}$ Assim, considerando que as atividades de EAN na escola têm expressivo potencial, faz-se necessário destacar que existe uma característica essencial a este processo: a importância de envolver todos os atores sociais no processo educativo, possibilitando ações coletivas de educação.

Entretanto, dentro da equipe escolar, existe um profissional que tem suas funções educativas invisibilizadas: o profissional responsável pelo preparo da alimentação escolar. São diversos os termos utilizados para designar esse profissional, e neste estudo será utilizado o termo "merendeira", devido a sua relevância histórica e cultural. Além disso, este substantivo estará no gênero feminino, já que este grupo é expressivamente composto por mulheres.

As merendeiras, além de realizarem o preparo da refeição, são o elo entre a alimentação escolar e os alunos. Considerando que a refeição possui potencial para se configurar como um momento educativo, essas profissionais poderiam ter suas habilidades educativas mais exploradas. ${ }^{5}$

Esse contexto fez emergir algumas questões, como: qual o papel que a merendeira exerce na alimentação escolar? Essas profissionais são potenciais educadoras no contexto da EAN no ambiente escolar? Quais são as possibilidades e desafios para sua atuação?

A partir destas questões, objetiva-se, no presente estudo, discutir o papel da merendeira no PNAE, assim como suas possibilidades e desafios nos processos e práticas de EAN, utilizando para tanto a metodologia de Grupo de Diálogos.

\section{Metodologia}

A metodologia utilizada neste trabalho foi a qualitativa, que objetiva descrever e decodificar os componentes de um sistema complexo de significados. ${ }^{6}$ É, portanto, oportuna para estudar temas relacionados às práticas alimentares, que têm referências na complexa dinâmica social.

A metodologia qualitativa também é interessante para estudar o ambiente escolar, já que nesse local o processo das relações humanas é dinâmico, interativo e interpretativo. ${ }^{7}$ As pesquisas qualitativas possuem características multimetodológicas e utilizam um número variado de métodos e instrumentos de coleta de dados.

Nesta pesquisa, a coleta de dados ocorreu em duas etapas. A primeira utilizou a técnica da observação participante, na qual existe o contato direto do pesquisador com o fenômeno estudado, com a finalidade de obter informações sobre a realidade das pessoas em seus próprios contextos e na ocorrência espontânea do fato. ${ }^{8}$ Sendo assim, conviveu-se durante três meses junto com oito merendeiras, realizando as tarefas inerentes a essas profissionais, sem que os outros atores 
sociais da escola soubessem que se tratava de uma pesquisa. A observação aconteceu no ambiente da cozinha-refeitório de duas escolas no Rio de Janeiro, uma estadual e outra municipal, quatro profissionais em cada escola.

Nesta fase foi possível participar das atividades pertinentes ao preparo e à distribuição da alimentação escolar, tendo como objetivo aproximar o pesquisador da realidade das merendeiras, possibilitando a identificação de alguns aspectos importantes relacionados ao papel dessa profissional em seu contexto de trabalho. Ao final de cada observação, os dados foram registrados no diário de campo, para não haver perda de informações relevantes e detalhadas sobre o que foi observado.

A partir desta etapa, foram elaborados os quatro possíveis caminhos para responder à questão: "Qual é o papel da merendeira na alimentação escolar?". Foram eles: Preparar e servir com amor, Educar através da alimentação, Cozinhar, Seguir as normas técnicas. Estes caminhos foram apresentados na forma de material impresso, e um vídeo reflexivo foi elaborado por um grupo de trabalho especificamente para este fim.

Na segunda etapa, a técnica utilizada foi a de Grupos de Diálogo (GD), que consiste em um grupo de pessoas que são convidadas a debater sobre determinada temática, visando à construção coletiva de opiniões por meio do diálogo.

A técnica de Grupos de Diálogo foi desenvolvida no Canadá, devido à inquietação em relação à lógica de dominação que perpassa as pesquisas de opinião no campo das políticas públicas, onde não há espaço para que os cidadãos reflitam antes de se posicionarem quanto ao tema. ${ }^{9}$ Passou por algumas adaptações para se adequar à realidade brasileira e ao ambiente escolar. ${ }^{10,11}$

Objetivou-se, por meio desta técnica, discutir o papel da profissional merendeira no PNAE, assim como suas possibilidades e limites nos processos e práticas de educação alimentar e nutricional. A intenção foi construir um espaço de interação entre os participantes, produtores de significados coletivos, já que as dificuldades encontradas no processo educativo na alimentação escolar não serão transpostas por um único sujeito, e exigem esforço e reflexão, além de práticas coletivas.

O grupo de diálogos ocorreu na rede municipal de ensino de uma cidade da Baixada Fluminense, emancipado havia pouco mais de uma década. A cidade possuía por volta de 170 mil habitantes, 33 unidades de ensino, onde estudavam cerca de 12 mil alunos e trabalhavam 1.600 funcionários. Destes, 120 diretamente no preparo da alimentação escolar.

As 23 merendeiras que compareceram ao Dia de Diálogos assistiram juntas ao vídeo. Depois elas se dividiram em quatro grupos, quando leram o material impresso, dialogaram a respeito e construíram cartazes com as conclusões de seu grupo, que posteriormente foram apresentados para toda a turma. Todos os diálogos foram gravados em áudio e acompanhados diretamente pelos pesquisadores. 
Os dados construídos durante o Dia de Diálogos por meio dos áudios, das anotações e dos cartazes foram analisados com muita cautela, respeitando-se a conjuntura em que as palavras eram ditas, tendo o cuidado de não utilizar os discursos descolados de seus contextos.

Para garantir o sigilo dos participantes, foi utilizado um código relativo ao número do grupo de que fizeram parte e a ordem em que se pronunciaram durante o Dia de Diálogos. Desta forma, por exemplo, se a merendeira pertenceu ao grupo 1 e foi a primeira a falar em seu grupo, foi nomeada de M1.1.

O trabalho foi aprovado pelo Comitê de Ética em Pesquisa do Instituto de Estudos em Saúde Coletiva da Universidade Federal do Rio de Janeiro (protocolo 288.335, em 17/04/2013). Todos os participantes leram e assinaram o termo de consentimento livre e esclarecido, conforme orientação do comitê.

\section{Resultados}

Durante o Dia de Diálogos, cada um dos quatro grupos produziu um cartaz, onde foi ilustrado o resumo do diálogo que eles estabeleceram após assistirem ao vídeo e lerem o material impresso. Os cartazes elaborados eram coloridos, com desenhos e letras enfeitadas; seu conteúdo indicava que atributos uma merendeira precisa ter e também alguns de seus desejos.

No cartaz do grupo 1 estava exposto um grande sol, que, segundo as merendeiras, poderia iluminar a vida delas. Além disso, estavam presentes dois corações, um com a inscrição "amor na cozinha"; o outro coração aparecia junto a um abacaxi, sinalizando que desejam receber mais carinho em detrimento das situações adversas que costumam enfrentar; também apareceram no cartaz frases associadas à tão desejada valorização.

O grupo 2 desenhou em seu cartaz um grande coração e dentro dele características que elas acreditam serem indispensáveis a uma merendeira. Responsável, pontual, dedicada, feliz, carinhosa e alegre foram os aspectos eleitos por este grupo. No verso, escreveram o que acreditam que as merendeiras merecem: respeito, bons salários, boas condições de trabalho e igualdade de direito com os outros profissionais da escola.

O coração também foi a figura central do cartaz do grupo 3, e dentro dele estava a cozinha escolar. Setas partiam deste coração, indicando características inerentes ao trabalho por elas praticado, onde constam a qualificação, o amor e a dedicação.

Já o grupo 4 não expôs nenhum desenho em seu cartaz, mas foi o único que fez menção direta aos caminhos apontados pelo vídeo e pelo material impresso. O grupo escolheu como resposta à questão proposta o caminho 2 - Educar através da alimentação, e o caminho 4 - Preparar alimentos 
saudáveis e sem contaminação. Além disso, o cartaz apresentou algumas reivindicações, como melhoria do material que recebem, o desejo de participação e de valorização.

Um quinto cartaz foi produzido coletivamente, após a apresentação de cada um dos grupos, onde as participantes destacaram que a merendeira possui papel educador, além de ter como função cozinhar com amor e profissionalismo, participar do planejamento da escola e do projeto político-pedagógico, integrar-se a todas as atividades realizadas na escola, ser responsável e trabalhar em equipe.

Outro item produzido pelos participantes foram as fichas pré e pós-diálogos, onde além de observar o grau de importância atribuído a cada um dos caminhos, também foi possível perceber os deslocamentos de opinião após o diálogo do grupo. Foram calculadas as médias dos valores por eles atribuídos na escala de 1 a 7 nas fichas pré e pós-diálogo, para cada um dos Caminhos do Diálogo, conforme a tabela 1.

Tabela 1. Média das opiniões dos participantes dos Grupos de Diálogos sobre cada um dos caminhos apresentados (n=23). Ficha pré e pós-diálogo. Rio de Janeiro, 2013.

\begin{tabular}{lcc}
\hline Caminhos & $\begin{array}{c}\text { Opção Média } \\
\text { Pré-Diálogo }\end{array}$ & $\begin{array}{c}\text { Opção Média } \\
\text { Pós-Diálogo }\end{array}$ \\
\hline Preparar e servir com amor & 6,86 & 6,61 \\
\hline Educar através da alimentação & 6,17 & 6,50 \\
\hline Cozinhar & 6,14 & 6,21 \\
\hline $\begin{array}{l}\text { Preparar alimentos saudáveis } \\
\text { e sem contaminação }\end{array}$ & 6,70 & 6,15 \\
\hline
\end{tabular}

Por meio dessas fichas, foi possível acompanhar a mudança de opinião pós-diálogo, que se encontra descrita na tabela 2, onde "menos favorável" se refere ao percentual de participantes que após o diálogo passou a atribuir menor nota ao caminho. Já o "permaneceu estável" se refere ao percentual que não alterou o valor atribuído ao caminho; e o "mais favorável" se direciona ao percentual que atribuiu maior valor ao caminho após o diálogo. 
Tabela 2. Deslocamento de opinião pré e pós-diálogo dos participantes dos grupos de Diálogos sobre cada um dos caminhos apresentados $(n=23)$. Rio de Janeiro, 2013.

\begin{tabular}{lccc}
\hline Caminhos & $\begin{array}{c}\text { Menos } \\
\text { favorável }\end{array}$ & $\begin{array}{c}\text { Manteve-se } \\
\text { estável }\end{array}$ & $\begin{array}{c}\text { Mais } \\
\text { favorável }\end{array}$ \\
\hline Preparar e servir com amor & $8,69 \%$ & $86,95 \%$ & $4,35 \%$ \\
\hline Educar através da alimentação & $0 \%$ & $78,26 \%$ & $21,74 \%$ \\
\hline Cozinhar & $26,08 \%$ & $56,52 \%$ & $17,39 \%$ \\
\hline $\begin{array}{l}\text { Preparar alimentos saudáveis } \\
\text { e sem contaminação }\end{array}$ & $13,04 \%$ & $82,61 \%$ & $4,35 \%$ \\
\hline
\end{tabular}

Os dados colhidos apresentaram que o primeiro caminho, referente à afetividade, foi o item que se manteve mais estável. O segundo, que expõe as possibilidades educativas, foi onde mais se observaram mudanças favoráveis, atribuindo maior nota ao caminho. Já o terceiro caminho, cozinhar, foi o que mais apresentou variação de opinião, e quando isso ocorreu, a maior parte das merendeiras lhe atribuiu nota inferior após o processo de diálogo. O mesmo foi observado em relação ao quarto caminho, que também apresentou redução das notas atribuídas nas fichas pós-diálogo.

Além dos cartazes e informações das fichas pré e pós, o Dia de Diálogos rendeu seis horas de gravação e 12 páginas de observação. Com base neste material, emergiram diversos sentidos e significados, que permitiram perceber que as merendeiras acreditam ter papel educativo e veem a afetividade e a qualificação como possibilidade; já a falta de integração e a limitação de tempo são vistas como desafios.

\section{Discussão}

Os dados coletivamente construídos indicaram que as merendeiras deste estudo reconhecem a função educadora como um de seus papéis na alimentação escolar. Por diversas vezes e em grupos distintos, estavam sempre presentes falas que reconheciam as merendeiras como profissionais da educação com enorme potencial para a EAN.

Durante a discussão em grupo, a respeito do caminho 2 (Educar através da alimentação), M1.1 afirmou: "Somos profissionais da educação, o professor sozinho não ensina nada." Neste mesmo contexto, M3.1 diz algo semelhante em outro grupo: "As merendeiras têm papel educador, não são só os professores que têm a função de educar." 
O mesmo pode ser observado na análise das fichas pré e pós-diálogo, onde foi possível perceber que, após o diálogo, as participantes atribuíram maior nota ao caminho da educação. Além disso, este caminho apresentou o maior deslocamento, aumentando o valor a ele atribuído na comparação das fichas pré e pós-diálogo.

As merendeiras apontaram que este potencial educativo se deve a sua proximidade com os alunos. Segundo as merendeiras, tal afinidade estimula o diálogo, pois, como afirmaram: "falam a língua deles", diluindo a autoridade e aproximando a conversa entre eles - merendeira/aluno e educador/educando - do diálogo verdadeiro.

Paulo Freire, ${ }^{12}$ em sua Pedagogia da Autonomia, destaca que ensinar exige disponibilidade para o diálogo. As merendeiras concordam e afirmam que quando este contato dialógico com os alunos acontece, pode ocorrer uma transformação, uma mudança no comportamento dos alunos. Nesse contexto, M4.1 afirmou pertinentemente: "É só uma questão de conversar, a gente conversa, eles provam e pedem para repetir, às vezes eles dizem que nunca experimentaram”. A frase abaixo destacada vai ao encontro da anterior:

Às vezes basta uma conversa para que a criança coma. Crianças mais velhas têm mais dificuldades no diálogo. Então vão as estratégias, é falar a língua deles. (M1.5).

A relação desenvolvida por merendeiras e alunos é permeada pelo afeto, e no Dia de Diálogos a amorosidade foi presença constante. Corações desenhados nos cartazes preparados pelos grupos, falas carinhosas e algumas histórias contadas deixavam transparecer o afeto que inunda o trabalho dessas profissionais. Esta relação é alimentada com o contato diário, com cada palavra falada e com cada olhar doce trocado.

O caminho "preparar e servir com amor", apresentado às merendeiras neste trabalho, teve destaque também nas fichas pré e pós-diálogo. Este caminho recebeu a maior nota média antes e após os diálogos em grupo; foi ainda o caminho onde as participantes menos mudaram de ideia, demonstrando a convicção que carregam neste quesito.

As merendeiras sentem que sua função é cuidar das crianças. São responsáveis por seu bemestar e se preocupam com a saúde de seus estudantes; acreditam ser as "mães da escola”, como uma delas escreveu na ficha pós-diálogo. Esse carinho é sentido pelos alunos, que o devolvem em forma de elogio à comida e agradecimentos - neste sentido, M4.1e M4.2 dividiram suas experiências:

Devemos ter em mente que precisamos alimentar as crianças com amor. Muitas vezes a criança passa mais tempo na escola do que em sua própria casa. Então precisamos ter consciência que, de alguma forma, somos responsáveis pelo seu bem-estar. (M4.1). 
Os alunos gostam mais da gente do que do resto da escola. Eu já fui homenageada na formatura do 9oano. Mesmo sobrecarregada, a gente arruma um tempo para um carinho, um abraço. A gente fala a língua deles, somos até comparados às mães, as mães da escola. (M4.2).

Este vínculo afetivo está diretamente relacionado às possibilidades educativas. Paulo Freire ${ }^{12}$ afirma que a afetividade e a amorosidade perpassam toda relação pedagógica, uma vez que sua razão de ser são os seres humanos em processo de humanização, onde os processos de aprendizado são constantes. Neste ponto, destaca-se uma fala que demonstra como as merendeiras reconhecem neste sentimento suas possibilidades educativas.

A gente tem consciência de que a gente é educador. Eu já pensei até de em ir de sala em sala... para fazer tipo uma palestra [...] porque a gente tem mais afinidade... assim era mais fácil aprender. (M1.2).

Entretanto, a afetividade não se acha excluída da cognoscibilidade. O desenvolvimento da inteligência é inseparável do mundo da afetividade - isto é, da curiosidade, da paixão, que, por sua vez, são a mola da pesquisa por novos conhecimentos. ${ }^{13}$ Desta forma, os conhecimentos e saberes também apresentam grande importância no processo de fortalecimento do potencial educativo das merendeiras.

No município onde foi realizado o Dia de Diálogos, as merendeiras acreditavam na essencialidade das capacitações. "Oferecer cursos de capacitação e reciclagem de funcionários é de suma importância!", afirmou M2.3 durante a apresentação de seu grupo para a turma. A alegação de M3.1 também ilustra esta afirmação: "Com certeza, o conhecimento técnico é primordial para um bom desempenho profissional".

Acreditavam que quanto mais cursos fizessem e mais conhecimentos possuíssem, melhor realizariam suas funções, como afirmou M3.3 durante a apresentação de seu grupo para a turma: "Somos profissionais qualificados para atender às exigências do setor". Assim, as capacitações contribuem para melhorar a autoestima e estimular a busca de novos conhecimentos.

As oportunidades educacionais têm-se apresentado como requisito fundamental para o empoderamento. A noção de empoderamento é situada, no pensamento de Paulo Freire ${ }^{14}$ como processo e resultado, emergindo de uma ação social na qual os indivíduos tomam posse de suas próprias vidas pela interação com outros indivíduos, e como estímulo para a participação de ações coletivas.

As merendeiras do munícipio estudado demostraram grande predisposição para participar das ações coletiva e se sentem preparadas para participar das tomadas de decisão que envolvem os aspectos da escola. Elas destacaram que desejam fazer parte, querem participar de tudo que ocorre na escola. 
Para tal, desejavam estar mais integradas à equipe escolar e acreditavam que este seja um desafio para sua função educativa, rompendo com as barreiras que as separam do corpo pedagógico da escola. Este cenário foi evidenciado no quinto cartaz, construído coletivamente, onde das seis funções que elas citaram, três estavam diretamente relacionadas à participação, foram elas: Participar do planejamento da escola e do Projeto Político-Pedagógico, integrar-se a todas as atividades da escola e trabalhar em equipe.

As merendeiras afirmaram que a participação delas é essencial a todas as ações na escola. M3.4 afirmou para seu grupo que "A cozinha é o coração da escola, por que todas as atividades da escola passam [...] dependem da alimentação". M3.5 completou: "O que pode mudar é que os profissionais da cozinha devem fazer parte do planejamento escolar”. Assim, foi possível perceber que, para essas profissionais, a inserção na equipe escolar favorece o exercício de seu trabalho, além de contribuir para sua autoestima, valorização e autonomia.

Maior integração com a equipe de nutrição da alimentação escolar também foi um desejo explicitado durante o diálogo. De maneira consensual, afirmaram que poderiam opinar de forma significativa na elaboração do cardápio. M3.3 destacou que "Tem que haver harmonia entre as merendeiras e o setor da nutrição, para um melhor empenho na cozinha, pois podemos ajudar no cardápio".

Com este mesmo olhar, Costa et al., ${ }^{15}$ em estudo que discute o PNAE como espaço de aprendizagem e construção de conhecimento, demonstram que todos da equipe escolar devem ter participação ativa nas discussões. Para as autoras, o conhecimento é construído por meio de processos interativos.

Muitas vezes, no entanto, fica delegada à merendeira somente a participação do que é imprescindível ao preparo da alimentação escolar e de maneira vertical. Foi possível verificar tal fato durante o grupo de diálogos, quando M4.5 afirmou que "[e]la [diretora] chega lá [na cozinha] e fala que chegou um e-mail e a partir de agora tem que fazer a comida assim ou assado, mas onde está o e-mail? Ela não mostra”.

No trabalho de Fernandes ${ }^{16}$ encontrou-se cenário semelhante, quando a inserção das merendeiras em atividades externas ao espaço cozinha-refeitório apresentou-se restrita. As profissionais entrevistadas afirmam que sua participação não ocorre com regularidade e que geralmente acontece na primeira reunião do ano e ao longo do ano letivo, apenas quando há algum problema ou modificação na alimentação escolar.

A dificuldade em efetivar a participação das merendeiras possui diversas raízes. Bezerra ${ }^{17}$ expôs que a visão da função da merendeira como técnica provoca, aparentemente, a desvinculação das merendeiras com os processos educativos, dificultando sua integração e participação. 
Já Teo et al. ${ }^{18}$ acreditam que essas restrições podem ser atribuídas à exclusão provocada pelos profissionais da escola e à autoexclusão gerada pela merendeira, por considerar seu trabalho extenuante, não restando, na prática, tempo para a participação em outras atividades.

"Tempo" foi um termo frequentemente mencionado durante o Dia do Diálogo, sendo sempre externado em uma perspectiva limitante, dificultando o trabalho das profissionais, e como um desafio a ser superado para que se alcancem os objetivos que consideravam importantes em suas rotinas diárias.

As merendeiras sofrem com a pressão do tempo, o que traz consequências negativas tanto em suas vidas pessoais, quanto na profissional. Nunes ${ }^{19}$ afirma que, em alguns casos, a dupla ou até tripla jornada não permite que elas tenham o tempo de descanso suficiente para repor as energias gastas no desempenho dessas atividades.

Durante o Dia de Diálogos, foi possível perceber que essas profissionais se ressentem por não ter o tempo que consideram adequado para a plena realização de suas funções: "O tempo não me deixa muitas vezes nem olhar para o rosto da criança, pois eu faço a distribuição sozinha", afirmou M2.2.

Por diversas vezes, indicaram o tempo como um fator limitante para a execução de seu trabalho, obrigando-as a deixar de realizar atividades que elas acreditavam ser importantes. Nesse contexto, M1.3 alegou: "Acho importante educar, mas muitas vezes não tenho tempo para conversar com os alunos". Já M4.1 afirmou: "A falta de mão de obra impede que a gente higienize adequadamente. Damos a fruta e pedimos para eles (alunos) lavarem, pois não tivemos tempo de fazer".

Outro aspecto que marca as atividades das merendeiras pela pressão do tempo se refere ao fato de que o trabalho delas é marcado por horários rígidos. Isso se deve ao cronograma das refeições e sua relação com a programação diária das aulas e intervalos: as profissionais se preocupam em ter sempre as refeições prontas nos horários predeterminados. Tal fato pode ser percebido na frase dita por M2.2 durante a apresentação de seu grupo:

Precisamos ter em mente muitas responsabilidades: como, por exemplo, a pontualidade. As refeições precisam ser servidas nas horas certas para que as crianças tenham o hábito de se alimentar na hora certa. (M2.2).

Nunes ${ }^{19}$ encontrou situação semelhante em seu trabalho, onde concluiu que na cozinha as atividades estão singularmente demarcadas pelo tempo, e que os horários de cada refeição são rígidos, devido à interferência que um atraso poderia causar nos horários das aulas. A autora também compara o trabalho da merendeira com a de uma "engrenagem" em linha de montagem. Por tudo isso, o tempo apresenta-se como uma barreira ao trabalho dessas profissionais. 
As frases ditas por elas evidenciaram, durante o diálogo, a vontade de orientar e estimular os alunos no período da alimentação, dialogando com eles, apresentando os alimentos que os estudantes não conhecem e encorajando-os a experimentar.

\section{Conclusão}

Durante este trabalho, ficou perceptível que essas profissionais dispõem de outras potencialidades no ambiente escolar, ultrapassando o ato puramente de cozinhar. O potencial educativo que estas profissionais apresentam emergiu nitidamente, já que com frequência agem na direção de estimular os educandos a se alimentarem de maneira adequada.

No contexto da dimensão educativa, destacaram-se no decorrer do diálogo dois fatores que as merendeiras possuem e ampliam seu potencial de educadora. A relação afetiva que estabelecem com os alunos é uma delas, pois esse afeto concebe um elo de confiança e torna mais fácil instaurar um diálogo, que é um meio fundamental para a aprendizagem.

O outro fator está relacionado ao desenvolvimento do conhecimento. Destacou-se a importância que essas funcionárias atribuíram aos cursos e treinamentos; por meio de conquista de conhecimento que ocorre nestes espaços, elas acreditam que ficam mais preparadas para exercer seu papel. Assim, tornam-se profissionais mais seguras, capazes de desenvolver atividades comumente delegadas somente aos professores, como o papel educativo.

A função educativa não foi unanimidade; algumas afirmaram não ser possível exercer este papel devido à falta de tempo. Assim, as merendeiras afirmam que "vencer" o tempo é um desafio diário, e que quando ele, o tempo, surge, conseguem atuar na dimensão educativa, já que podem estimular os alunos a aceitarem a refeição e apresentar aos educandos alimentos que eles não conhecem.

Também aparece como desafio a falta de integração com a equipe pedagógica e de nutrição. As merendeiras acreditam que podem contribuir para a organização escolar e com o planejamento do cardápio, pois possuem olhares nos diversos ambientes da escola, com observações colhidas e elaboradas nos demais espaços que não os da sala de aula.

Faz-se essencial construir uma escola mais dialógica e mais democrática, onde os diferentes atores sociais da escola desenvolvam um olhar atento para as potencialidades das merendeiras. É importante que se desenvolvam outros estudos nesta direção, identificando e valorizando os diferentes papéis, em especial a função educativa que essas profissionais apresentam.

Construir um caminho neste sentido pode ser interessante para contribuir na transposição do caráter puramente assistencialista que muitos enxergam no PNAE e, assim, usufruir ainda mais do potencial educativo desse programa. 


\section{Colaboradores}

Gomes KS e Fonseca ABC Brasil trabalharam em todas as etapas, desde a concepção do estudo até a revisão da versão final do artigo.

Conflito de interesses: Os autores declaram não haver conflitos de interesses.

\section{Referências}

1. Brasil. Fundo Nacional de Desenvolvimento da Educação. Governo federal transfere $\mathrm{R} \$ 338,9$ milhões para alimentação e transporte escolar. Acesso em: 21 ago. 2017. Disponível em: http://www.fnde. gov.br/acesso-a-informacao/institucional/area-de-imprensa/noticias/item/6101-governo-federaltransfere-r\$-338,9-milh\%C3\%B5es-para-alimenta \%C3\%A7\%C3\%A3o-e-transporte-escolar

2. Santos, LA. Educação alimentar e nutricional no contexto da promoção de práticas alimentares saudáveis. Rev Nutrição. 2005; 18(5):681-692.

3. Brasil. Lei Federal n. 11947, de 16 de junho de 2009. Dispõe sobre o atendimento da alimentação escolar e do Programa Dinheiro Direto na Escola aos alunos da educação básica. Diário Oficial da União. 17 jun. 2009.

4. Brasil. Portaria Interministerial n 1.010, 08 de maio de 2006. Institui as diretrizes para a promoção da alimentação saudável nas escolas de educação infantil, fundamental e nível médio das redes públicas e privadas, em âmbito nacional. Diário Oficial da União. 09 maio 2006.

5. Monlevade JAC. Funcionários das escolas públicas: educadores profissionais ou servidores descartáveis? Brasília: Idéa; 2001.

6. Neves JL, Pesquisa qualitativa: características, usos e possibilidades. Cadernos de Pesquisa em Administração. 1996; 1(3):1-5.

7. Oliveira MMD. Como fazer pesquisa qualitativa. In: Oliveira MMD. Como fazer pesquisa qualitativa. Petrópolis: Vozes; 2013.

8. Portronieri FRDS. O jovem, o comer e o perceber-se: concepções de alunos e professores sobre o corpo, alimentação e a saúde em uma escola municipal do Rio de Janeiro [dissertação]. [Rio de Janeiro]: Núcleo de Tecnologia Educacional para a Saúde, Universidade Federal do Rio de Janeiro; 2010.

9. Yankelovich D, Rosell S, Gantwerk H, Friedman W. The next big step in deliberative democracy. Kettering Review. 2006; Fall:54-66.

10. Leão G, Dayrell J, Gomes NL. Juventude brasileira e democracia: participação, esferas e políticas públicas, 2. Relatório Global. Rio de Janeiro: Instituto POLIS, IBASE; 2006.

11. Greenwood RL. O cotidiano escolar permeado pelo direito à alimentação: um diálogo com os atores sociais da escola [dissertação]. Rio de Janeiro: Universidade Federal do Rio de Janeiro, Núcleo de Tecnologia Educacional para a Saúde; 2011.

12. Freire P. Pedagogia da autonomia. Rio de Janeiro: Paz e Terra; 2000. 
13. Morin E. Os sete saberes necessários à educação do futuro. 2. ed. São Paulo: Cortez; 2000.

14. Freire P. Pedagogia do oprimido. Rio de Janeiro: Paz e Terra; 1983.

15. Costa EQ, Ribeiro ECO, Ribeiro VMB. Programa de Alimentação Escolar: espaço de aprendizagem e produção do conhecimento. Rev Nutrição. 2001; 14(3):225-229.

16. Fernandes AGS. Alimentando o saber: o perfil das merendeiras, suas percepções em relação ao ofício e as possibilidades para a educação [dissertação]. Rio de Janeiro: Universidade Federal de Rio de Janeiro, Núcleo de Tecnologia Educacional para a Saúde; 2012.

17. Bezerra JAB. Comer na escola: significados e implicações [tese]. Fortaleza: Universidade Federal do Ceará, Faculdade de Educação; 2002.

18. Teo CRPA, Sabedot FRB, Schafer E. Merendeiras como agentes de educação em saúde da comunidade escolar: potencialidades e limites. Revista Espaço para a Saúde 2010; 11(2):11-20.

19. Nunes BO. O sentido do trabalho para merendeiras e serventes em situação de readaptação nas escolas públicas do Rio de Janeiro [dissertação]. Rio de Janeiro: Fundação Oswaldo Cruz, Escola Nacional de Saúde Pública; 2000.

Recebido: 17 de novembro, 2017

Revisado: 05 de fevereiro, 2018

Aceito: 19 de fevereiro, 2018 